\title{
Knowledge, attitudes and practices regarding modern methods of postpartum contraception among postnatal mothers
}

\author{
Dasanayake DLW ${ }^{1}$, Dilhani BWGI² \\ ${ }^{\prime}$ Department of Obstetrics \& Gynecology, ${ }^{2}$ Allied Health Science Degree Programme, Faculty of Medicine, \\ University of Ruhuna, Galle, Sri Lanka .
}

Correspondence: Dr. DLW Dasanayake

e-mail: lanka.dasanayake@yahoo.com

https://orcid.org/0000-0003-4330-9641

\begin{abstract}
Introduction: Improving postpartum contraceptive use is an important programmatic strategy to improve the health and well-being of women, newborns and children in a country. The aim of this study was to assess the knowledge, attitudes and practices regarding postpartum contraception among postnatal mothers.

Methods: A cross sectional study on 300 postnatal mothers was carried at Teaching Hospital Mahamodara (THM) Galle. Multiparous mothers were recruited using convenient sampling method. Data collection was done using a validated, self-administered structured questionnaire after obtaining informed consent. Questionnaire was designed to assess on knowledge, attitudes and practices of postpartum contraception.

Results: Level of knowledge regarding postpartum contraception was above average in $15.8 \%$ of mothers and below average in $46.6 \%$ of them. The majority of them were aware regarding Combined Oral Contraceptives Pills (COCP). Almost $60 \%$ of women of Islamic and Hindu religions believed that contraception is not accepted by their religion. Among postnatal mothers, $70.2 \%$ had previous practices of postpartum contraception and the commonest method used was COCP. Approximately $76 \%$ of mothers gained information regarding postpartum family planning from Public Health Midwives (PHM).

Conclusions: Knowledge on post-partum contraception in general was inadequate. The attitudes and practices on postpartum contraception were influenced by their religion. Short acting contraceptives were popular method of contraception among postnatal mothers. The major information provider was PHM.
\end{abstract}

Keywords: Postpartum contraception, knowledge, attitudes, practices

\section{Introduction}

Fertility control with the use of contraceptives is essential to the health and well-being of individuals, family and community. It has been noted that demand fluctuates over the course of reproductive life. Childbirth changes priorities, attitudes and lifestyles of women. Postpartum period is particularly important because adequate birth spacing can improve maternal and infant health (1).

The majority of women resume sexual activity within several weeks of the delivery. The amount of time following delivery that a woman is infertile is highly variable and dependent on multiple factors, including breastfeeding status. Ovulation can occur even if the mother has not resumed menstruation and could happen as early as 25 days postpartum. The probability of ovulation occurring before resumption of menstruation increases over time (2).

Postpartum family planning (PPFP) focuses on the prevention of unintended and closely spaced pregnancies through the first 12 months following childbirth (3). 
Globally unmet needs for contraception of women remain high despite of availability of modern safe and effective contraceptive methods. Yet unmet need is constituted a large percentage of total demand in many countries. Unmet need for family planning in Sri Lanka is $15 \%$ (4).

Unmet needs could lead to unplanned and unintentional pregnancies which will increase the risk of adverse maternal and neonatal health outcomes. Improving postpartum contraception is an important programmatic strategy to improve the health and well-being of women, newborns, and children (1).

Postpartum contraceptive advice allows women to plan the spacing and number of future children. Short inter-pregnancy intervals have been associated with an increased risk of adverse perinatal outcome; therefore aside from the socioeconomic benefits, delaying future pregnancies may be beneficial in terms of health (5). Postpartum women face uncertainty about timing of return to fecundity. Many women wait to use contraception until menses return, resulting in unintended pregnancies (6).

The choice of a postpartum contraceptive method depends on many factors, including the need for a temporary versus a permanent method, the infant feeding choice and the extent to which informed consent is made prior to delivery. For maximum protection, the non-breastfeeding woman should be protected from the fourth week postpartum, even if that means using a temporary method, such as condoms, until her method of choice is certain (7).

The postnatal period is associated with physio-logical, psychological and social changes, which can influence sexual and reproductive health. Although women may wish to delay or avoid further pregnancy, they may not know how to access contraception or which methods are safe to use, particularly if they are breastfeeding. There may also be difficulties with sexual function and relationships during this time, for which individuals may require information and support (5).

Postpartum contraception is a subject which has been discussed worldwide and it is very important for improvement of their economy. Nearly twothirds of women in first postpartum year had inadequate contraception in United States of America, for example, nearly $60 \%$ of pregnancies conceived at any time are unplanned $(23 \%$ unintended and 37\% mistimed) (8). Surveys from 27 countries indicate that two-thirds of postpartum women had an unmet need for contraception (9).

Ninety five percent of women in low and middleincome countries wish to avoid a pregnancy within next two years, but $70 \%$ are not using any method of contraception (10). Common reasons for unmet need for family planning were inconvenience, unsatisfactory services, lack of information, fears about contraceptive side effects and opposition from husbands, relatives or others (11).

In Sri Lanka, the most common reason for illegal termination of pregnancy is youngest child being too young (12). This largely reflects the unmet need among postnatal mothers.

Unmet needs among Sri Lankan women remains approximately 7\% among postnatal mothers (13). One of the most common reasons is lack of knowledge regarding different type of contraception methods. The aim of this study was to assess the knowledge, attitudes and practices regarding postpartum contraception among postnatal mothers.

\section{Methods}

A descriptive cross sectional study was carried out at Teaching Hospital Mahamodara. Mothers who were in immediate postpartum period were recruited for the study. Postnatal mothers who were not able to read, acutely unwell, suffering from psychiatric illnesses and in intensive care unit were excluded from the study. Three hundred consecutive postnatal mothers were recruited from four postnatal wards during the periods of three months from March to May 2015. Eight postnatal mothers were excluded from the study. Data were collected using a pretested self-administered questionnaire that included four sections to evaluate the knowledge, attitudes and practices regarding postpartum contraception among postnatal mothers. It consisted of both open and close ended questions. Section one was designed to obtain basic socio-demographic data. Section two consisted of 33 facts to assess their knowledge about postpartum family planning. Section three was designed with 20 facts to evaluate their attitudes regarding PPFP practices. Section four consisted of four subsections to assess previous practices regarding PPFP. Questions assessing knowledge, attitudes and practices were assigned scores using 
predetermined cut-off values. One hundred points were allocated to 33 facts to assess their knowledge about postpartum family planning Postnatal mothers were categorized in to above average (score $>60$ ), average (score 41 to 60 ) and below average (score $<40$ ) on levels of overall knowledge. Ethical approval was granted by ethical committee of the Faculty of Medicine, University of Ruhuna. Permission for collecting data in hospital was obtained from the Director of the THM.
Participants were fully informed about the purpose of the study and obtained the written informed consent. The privacy and confidentiality of each participant taking part in study was ensured.

Data was entered in to a data base created using Statistical Package for Social Sciences (SPSS) version 20. Data analysis and result presentation were done using mean, $p$ value, standard deviation (SD) and percentages.

\section{Results}

Table 1: Basic characteristics of the sample

\begin{tabular}{|c|c|c|c|}
\hline \multicolumn{2}{|c|}{ Socio demographic characteristics } & \multicolumn{2}{|c|}{ Percentage $(n=292)$} \\
\hline Age & $20-29$ & $32.9 \%$ & (96) \\
\hline & $30-39$ & $61 \%$ & $(178)$ \\
\hline & $40-49$ & $5.8 \%$ & (18) \\
\hline \multirow[t]{3}{*}{ Religion } & Buddhist & $89 \%$ & $(260)$ \\
\hline & Islam & $9.6 \%$ & $(28)$ \\
\hline & Christian & $1.4 \%$ & (4) \\
\hline \multirow[t]{3}{*}{ Ethnicity } & Sinhala & $88.4 \%$ & $(258)$ \\
\hline & Muslim & $10.3 \%$ & (30) \\
\hline & Tamil & $1.4 \%$ & (4) \\
\hline \multirow[t]{5}{*}{ Level of education } & Up to $\mathrm{O} / \mathrm{L}$ (secondary) & $43.8 \%$ & $(128)$ \\
\hline & Up to $\mathrm{A} / \mathrm{L}$ (secondary) & $38 \%$ & $(111)$ \\
\hline & Diploma (high) & $4.1 \%$ & (12) \\
\hline & Degree (high) & $5.5 \%$ & (16) \\
\hline & Under grade 10 (primary) & $8.6 \%$ & $(25)$ \\
\hline \multirow[t]{3}{*}{ Marital status } & Married & $97.9 \%$ & $(286)$ \\
\hline & unmarried & $1.7 \%$ & (5) \\
\hline & Divorced & $0.3 \%$ & (1) \\
\hline \multirow[t]{5}{*}{ Income } & Not mentioned & $10.6 \%$ & $(31)$ \\
\hline & $1-10,000$ & $8.2 \%$ & (24) \\
\hline & $10,001-50,000$ & $74 \%$ & $(216)$ \\
\hline & $50,001-100,000$ & $6.8 \%$ & $(20)$ \\
\hline & $>100,000$ & $0.3 \%$ & (1) \\
\hline \multirow[t]{4}{*}{ No of children } & 2 & $63.7 \%$ & $(168)$ \\
\hline & 3 & $27.7 \%$ & (81) \\
\hline & 4 & $6.8 \%$ & (20) \\
\hline & $\leq 5$ & $1.7 \%$ & (5) \\
\hline
\end{tabular}

According to the age distribution of the sample, majority (61\%) was in 30-39 years age group. Almost $90 \%$ of mothers were Sinhala Buddhist. Approximately $80 \%$ of mothers have had educational level up to ordinary level or above (Table 1). 
Table 2: Overall level of knowledge on postpartum contraception

\begin{tabular}{|c|c|}
\hline Level of knowledge & Percentage $\%(n=292)$ \\
\hline $0-40 \quad$ (Below average) & $46.6 \%(136)$ \\
\hline $41-60$ (Average) & $37.7 \%(110)$ \\
\hline$>60 \quad$ (Above Average) & $15.8 \% \quad(46)$ \\
\hline
\end{tabular}

Table 3: Willingness of participants to use a contraceptive method after a child birth

\begin{tabular}{cl}
\hline Willingness to use contraceptives & Percentage $(\mathbf{n}=\mathbf{2 9 2})$ \\
\hline Yes & $83.6 \%(244)$ \\
No & $16.4 \% \quad(48)$ \\
\hline
\end{tabular}

Table 4: Beliefs regarding post-partum contraception

\begin{tabular}{llrrr}
\hline & \multicolumn{3}{c}{ Yes (\%) } & \multicolumn{2}{c}{ No (\%) } \\
\hline Delayed till next pregnancy & $88.7 \%$ & $(259)$ & $11.3 \%$ & $(33)$ \\
Not accepted by the religion & $8.9 \%$ & $(26)$ & $91.1 \%$ & $(266)$ \\
Sexual satisfaction is minimal & $7.5 \%$ & $(22)$ & $92.5 \%$ & $(270)$ \\
Fear of side effects & $44.2 \%$ & $(129)$ & $55.8 \%$ & $(163)$ \\
Doubts regarding instructions & $5.8 \%$ & $(17)$ & $94.2 \%$ & $(257)$ \\
\hline
\end{tabular}

Table 5: Percentages usage of different types of contraceptive methods after previous child birth

\begin{tabular}{llc}
\hline & \multicolumn{2}{c}{ Percentage (\%) } \\
\hline Combined Oral contraceptive Pills & $40.4 \%$ & $(83)$ \\
Injectables (DMPA) & $20 \%$ & $(41)$ \\
Progesterone containing implant (Judella ) & $1.46 \%$ & $(3)$ \\
IUD (Copper T) & $20 \%$ & $(41)$ \\
Male condoms & $17 \%$ & $(35)$ \\
Female condoms & $0 \%$ & $(0)$ \\
Emergency pills (Levonorgestrel) & $0.4 \%$ & $(1)$ \\
Emergency IUD & $0.4 \%$ & $(1)$ \\
Others & $0.4 \%$ & $(1)$ \\
\hline
\end{tabular}


Approximately half of mothers had poor knowledge regarding postpartum contraception (Table 2).

Out of 292 postnatal women more than $80 \%$ women wished to use some type of contraceptive after the child birth (Table 3).

Approximately $10 \%$ of mothers believed religion is a deciding factor for contraception and $45 \%$ mothers has had fear of using a contraceptive method due to its side effects (Table 4).

A vast majority $(70 \%)$ used some type of contraceptive method following their previous childbirth (within first six months).

Almost $40 \%$ of mothers had used COCP as a postpartum contraceptive method following previous child birth (Table 5).

Majority of women (76\%) had gained their knowledge regarding PPFP from Family Health Workers. Approximately $10 \%$ of them acquired information from both doctors and nurses. Media helped to gather knowledge only in $2.7 \%$ of women.

\section{Discussion}

The study found that overall knowledge about PPC is generally inadequate among postnatal mothers. Vast majority of postpartum mothers wished to use some kind of contraceptive method to space-out next pregnancy. Two third of mothers have practiced PPFP following last child birth and among them most popular method had been COCP. Family Health Worker had been the major source of their awareness.

Even though we expected high level of knowledge among postnatal mothers, this study revealed inadequate knowledge regarding PPC.

When considering attitudes, vast majority of women $(83 \%)$ wanted to have some type of contraceptive after child birth. But half of them afraid due to side effects of the contraceptive methods. Significant number of non-Buddhist women believes that contraceptive usage is not accepted by their religion. A 2010 analysis of Demographic and Health Survey data from 17 countries demonstrated that $50-88 \%$ of women in the first year of postpartum period would like to avoid pregnancy but are not using contraception. Policy efforts for providing familyplanning services to postpartum women have primarily focused on the first six weeks after delivery, but the extension of services through the first year postpartum is likely to further improve birth spacing. WHO recommends an interval of 24 months or more before attempting a next pregnancy after a live birth, to reduce the risks of adverse outcomes for mother and child (14). This study shows that the majority of mothers did not know exact timing of using PPC although they were aware regarding contraceptive methods.

In our study $70.2 \%$ mothers had previous practice of postpartum contraception and the most popular method had been the COCP. According to Cooper et al, approximately one third of women were using a modern contraceptive method in his study (6). In the second decade of the $21^{\text {st }}$ century, the best available figures suggest that the contraceptive pills and the condom remain the most widely used methods in Britain (9). LARC (long acting reversible contraceptives) has high acceptance rate as postpartum contraception in our study population following previous child birth. This is a healthy trend. Kari et al identified across states, that there was a wide range of use of female sterilization and long-acting reversible contraception. Practice of LARC increased $\geq 18 \%$ per year, while use of injectables and oral contraceptives declined by $2.5-10.6 \%$ annually (15). LARC should be encouraged by health care profession as most effective contraceptive method.

Of the mothers those who have had previous practice of postpartum contraception $(\mathrm{n}=205)$, majority (93\%) mentioned that the commonest sources information gained was from family health workers. This is probably due to family health worker being their first contact care giver in the community.

However we must encourage other health professionals to counsel mothers at different levels of contact to reduce unmet need of contraception.

\section{Conclusions and recommendations}

Knowledge on post-partum contraception in general was inadequate among postnatal mothers. Vast majority of postpartum mothers wished to use some kind of contraceptive method to space-out next pregnancy. Two thirds of mothers have practiced PPFP following last child birth and 
among them most popular method had been COCP. Family Health Worker had been the major source for their awareness.

We highly encourage health care professionals to counsel eligible couples and postnatal mothers regarding PPFP. This can be facilitated through setting guidelines by policy makers. Modern methods of contraception, specially LARC should be freely available in the family planning clinics for informed choice.

\section{References}

1. Shrah LB. Family Planning Advice and Postpartum Contraceptive Use Among Low-Income Women in Mexico. International Family Planning Perspectives 2007;33(1): 6-12.

2. $\mathrm{DHMH} / \mathrm{FHA} / \mathrm{CMCH}$ Mariland family planning \& reproductive health program clinical guidelines. Postpartum Evaluation and Contraception, 2012:14.Available at: http://phpa.dhmh.maryland.gov/mch/ Documents/ Family_Planning_Guidelines/1.13,Gyn, Postpartum Evaluation AndContraception,Final,2012.pdf [Accessed 20 June 2015]

3. World Health Organization (WHO). Programming strategies for postpartum family planning. WHO. 2013. ISBN:9789241506496 [online]. Available at: www.who.int/ reproductivehealth/.../family_ planning/ppfp_strategies/en/ [Accessed 19 July 2015].

4. Westoff, CF and Ochoa LH (1991). Unmet Need and Demand for Family Planning. Demographic and Health Surveys Comparative Studies 5. Columbia, MD: Institute for Resource Development/ Macro International Inc. Available at: http://www.popline.org/node/315238 [Accessed 05 December 2014].

5. Faculty of sexual and reproductive health care clinical effectiveness unit, postnatal sexual and reproductive health. (2009) Faculty of sexual and reproductive health. Available at: http://www.fsrh.org/pdfs/ceuguidance postnatal og.pdf [Accessed, 11 November 2014].

6. Cooper CM, Ahmed S, Winch PJ, Pfitzer A, McKaig C, Baqui AH. Findings from use of a narrative story and leaflet to influence shifts along the behavior change continuum toward postpartum contraceptive uptake in Sylhet District, Bangladesh. Patient Educ Couns. 2014; 97(3): 376-382.
7. Kenned K (2014). Post-Partum Contraception [online] Available at: http://www.ncbi.nlm.nih.gov/pubmed/ 87367220 [Accessed, 7 November 2014]

8. Andrew MK (2015). Post abortion contraception. UpToDate. available at: http://www.uptodate.com/ contents/postabortion-contraception [Accessed, 12 July 2015].

9. Dhadwal V. Education for contraceptive use by women after childbirth: RHL commentary (last revised: 1 December 2012). The WHO Reproductive Health Library; Geneva: World Health Organization. http://apps.who.int/rhl/ pregnancy_childbirth/care_after_childbirth/cd001863_ dadhwalv_com/en/index.html [Accessed, 20 June 2015].

10. Gaffield ME, Egan S, Temmerman M. It's about time: WHO and partners release programming strategies for postpartum family planning. Global Health, Science and Practice. 2014; 2(1): 4-9. doi:10.9745/GHSP-D-13-00156.

11. Mahmood SE, Srivastava A, Shrotriya VP, Shaifali I and Mishra P (2011). Postpartum Contraceptive Use in Rural Bareilly. Indian Journal of Community Health, 23(2): 56-57.

12. Senanayake H (2011). Induced abortion in Sri Lanka. Ceylon Medical Journal 49(1), pp.1-4.

13. Unmet need for family planning, total, percentage. United Nations Statistics Division. 2011; Available at: http://data.un.org/Data.aspx?d=MDG\&f=seriesRowID\%3 A764.

14. Sonalkar S, Mody S and Gaffield M (2017). Outreach and integration programs to promote family planning in the extended postpartum period. International Journal of Gynaecology and Obstetrics 2014 Mar; 124(3): 193-7.

15. Kari W, Joseph E, Kristine H, Daniel G. Variation in postpartum contraceptive method use: results from the Pregnancy Risk Assessment Monitoring System (PRAMS) International reproductive health journal of Contraception 89(1): 57-62. 